Revista Iberoamericana, Vol. LXX, Núms. 208-209, Julio-Diciembre 2004, 983-1001

\title{
PUBLICACIONES PERIÓDICAS GAY, LÉSBICAS, TRAVESTIS Y TRANSEXUALES EN BRASIL: COMUNIDAD Y CULTURA ${ }^{1}$
}

\author{
POR \\ RoBert Howes \\ King's College, Londres
}

Este artículo estudia las publicaciones periódicas dirigidas a los intereses de gays, lesbianas, travestis y transexuales en el Brasil. Sitúa estas publicaciones en el contexto de la prensa alternativa y del surgimiento de una comunidad gay, y considera su importancia en el desarrollo de la cultura gay. Sugiere modos de clasificar las publicaciones periódicas gay según tipo y fecha, y ofrece un análisis general de las principales publicaciones que han sido editadas en los últimos cuarenta años. Luego analiza el modo en que algunas de las publicaciones más influyentes y de mayor duración han tratado los temas de la identidad, la comunidad y la cultura gay, y finaliza con algunas breves reflexiones sobre la creciente influencia de la Internet.

Se ha escrito mucho sobre los medios masivos y su papel en el discurso dominante en la cultura y la sociedad de todo el mundo. Se ha prestado mucha atención a la radiodifusión y a los principales medios gráficos, tales como periódicos y, en menor medida, revistas de gran circulación. Ha habido asimismo un intento de hacer una teoría sobre las revistas desde una perspectiva histórica, por ejemplo en relación con las publicaciones de la época victoriana, vistas cada vez más como una de las manifestaciones culturales más importantes del siglo xix (Brake, Jones y Madden). Sobre los medios alternativos se ha escrito menos, aunque hay un creciente interés en ellos, que son vistos como sitios de resistencia que ofrecen un vehículo para transmitir posiciones opuestas al discurso hegemónico. La prensa alternativa tiene una larga historia, y ha jugado un papel decisivo en acontecimientos tales como la Reforma, la Guerra Civil Inglesa y la Revolución Francesa. En la segunda mitad del siglo xx cobró nuevo vigor con el desarrollo de nuevas tecnologías de comunicación e impresión que abarataron y facilitaron la publicación, poniéndola al alcance de los grupos hasta entonces marginados.

En la actualidad, buena parte del interés de los investigadores se concentra en el estudio del nuevo medio de la Internet, pero hay también una creciente conciencia sobre el rol del periodismo impreso como comunicador y como espacio de puntos de vista alternativos. Mientras algunos trabajos han intentado ofrecer una mirada general sobre

\footnotetext{
${ }^{1}$ Agradezco a las siguientes personas e instituciones por la ayuda que me ofrecieron proveyéndome de material para este artículo: Aquiles Brayner, James Green, el difunto João Antônio Mascarenhas, Luiz Mott y el equipo del Arquivo Edgard Leuenroth, Universidad de Campinas, y la Associação Brasileira Interdisciplinar de AIDS.
} 
muchos grupos que producen publicaciones alternativas, otros se han concentrado en publicaciones de una comunidad particular, como la de los negros en Gran Bretaña, o sobre algún tipo de publicación, como los periódicos locales alternativos (Atton; Kunoff; Benjamin; Minority Press Group). En el Brasil, los orígenes de la prensa alternativa pueden rastrearse en los periódicos anarquistas y de la clase obrera en la Primera República (1889-1930). La prensa alternativa, a veces llamada “imprensa nanica”, asumió un papel importante en los años setenta como opositora del régimen militar, empeñada como estaba en preservar algunos vestigios de libertad de prensa ante la censura gubernamental. De particular importancia fueron las revistas satíricas Pasquim y los periódicos de opinión política como Opinião y Movimento (Aquino).

La prensa lésbica y gay nació como una manifestación de la prensa alternativa, pero también está estrechamente vinculada al desarrollo del movimiento lésbico y gay. Éste se inició en Alemania a fines del siglo xıx como parte de la campaña para rechazar la sección 175 del Código Penal alemán, que prohibía las relaciones homosexuales entre hombres. Esta primera etapa encontró un final abrupto en 1933, con el ascenso de Hitler y los nazis al poder. La segunda etapa se inició después de la Segunda Guerra Mundial, con la fundación de grupos gay en Escandinavia, Holanda y los Estados Unidos. El movimiento adquirió relevancia internacional con la parcial descriminalización de la homosexualidad masculina en Inglaterra en 1967, resultado del proceso de reforma parlamentaria, y, de modo más importante, con la protesta de Stonewall en Nueva York en 1969, una violenta respuesta a la represión policial que llevó a la fundación del Gay Liberation Front. La ideología de liberación gay rechazó el planteo asimilacionista y cauteloso de los primeros militantes homosexuales y llamó a lesbianas y gays a asumir su sexualidad abiertamente y con orgullo, a luchar contra la discriminación social y legal y, en su inicial milenarismo, a luchar por la liberación de toda la sexualidad. Durante los años setenta los movimientos de liberación gay se propagaron por el mundo occidental, incluyendo América Latina, con la creación de grupos gay en Argentina (1969-), México (1972-) y Puerto Rico (1974-). El inicio de la crisis del SIDA en los años ochenta provocó una tragedia humana y ocupó a muchos activistas en el combate contra los efectos de la epidemia. Sin embargo, el trabajo político continuó y, a pesar de algunos retrocesos, hacia el final del siglo xx hubo una marcada disminución en la discriminación gubernamental y un mayor reconocimiento de los derechos humanos de gays y lesbianas en la mayoría de los países occidentales.

En Brasil, la homosexualidad no era ilegal, aunque las autoridades utilizaron diversas medidas legales y policiales para controlar la conducta homosexual en público, y las presiones familiares tuvieron una fuerte influencia. Los gays venían reuniéndose informalmente en grupos sociales desde hacía mucho tiempo, pero el primer grupo gay con un propósito político explícito fue Somos: Grupo de Afirmação Homossexual, que comenzó reuniéndose en São Paulo en 1978 (Macrae). Esto inspiró la creación de otros grupos, que crecieron velozmente en número, alcanzando un total de veintidós en 1980, cuando tuvo lugar en São Paulo el primer Encontro Nacional del Movimiento Gay. Desacuerdos ideológicos y políticos y animosidades personales llevaron a una serie de divisiones muy publicitadas y a la desilusión. El número de grupos cayó rápidamente desde 1982, alcanzando el punto más bajo en 1985. A pesar de esta experiencia desalentadora, el movimiento gay sobrevivió, y desde fines de los ochenta comenzó a 
crecer de nuevo en forma gradual, ayudado por el activismo vinculado al SIDA y por la financiación pública de la labor de prevención (Green, "Desire”, "Emergence”, “More love"; Trevisan, Devassos). A mediados de 2001, se contaban aproximadamente unos cincuenta grupos militantes gay y un total de aproximadamente noventa organizaciones gay en el Brasil. ${ }^{2}$

El crecimiento del movimiento internacional lésbico y gay en los años setenta acompañó el desarrollo de una comunidad gay autoconsciente y se reflejó en el crecimiento de su prensa. Hacia el final de la primera década de la liberación gay, esta comunidad podía sostener una cantidad de periódicos de aparición regular, frecuentemente en formato tabloide, tales como The Advocate (Los Angeles, 1967-), Gay Community News (Boston, 1973-), The Body Politic (Toronto, 1971-1987), Gay News (London, 1972-1983) y GaiPied (París, 1979-1992). Éstos transmitían noticias, comentarios políticos y los valores de liberación gay de la comunidad, que a un tiempo reflejaban y contribuían a formular. En el más conservador clima cultural norteamericano y europeo de los años ochenta, estas publicaciones desaparecieron o se vieron obligadas a modificar su estilo. Hoy el mercado está dominado por revistas en papel ilustración, de las cuales algunas todavía se ocupan directamente de las preocupaciones culturales y políticas de la comunidad lésbica y gay, tales como Gay Times (Londres, originalmente Him Monthly, 1974-) y Babilonia (Milán, 1982-), mientras otras se volcaron de modo creciente a la corriente general, adoptando un estilo más consumista y concentrándose en la moda y el estilo de vida gay, tales como Out (Nueva York, 1992-) y Attitude (Londres, 1994-).

Los investigadores de los tópicos lésbicos y gay han utilizado frecuentemente las publicaciones periódicas y los periódicos de noticias como una fuente de material, pero han estudiado relativamente poco las publicaciones mismas. Sanderson ha estudiado la representación de lesbianas y gays en los medios convencionales en Gran Bretaña, y muchas revistas gay traen un resumen regular sobre algún comentario reciente de un periódico. De un modo detallado y abarcador, Streitmatter ha dado cuenta de la prensa gay y lésbica en los Estados Unidos desde la Segunda Guerra Mundial. Han aparecido también algunos estudios esporádicos sobre publicaciones periódicas individuales editadas por y para la comunidad gay. Los investigadores han escrito sobre determinadas publicaciones, tales como la antigua publicación periódica suiza Der Kreis y la taiwanesa G\&L Magazine, y periodistas gay han ofrecido desde el interior del movimiento informes sobre eventos críticos, como por ejemplo el cierre del pionero periódico inglés, Gay News (Kennedy; Erni \& Spires; Hanscombe). Se ha realizado una serie de estudios y de reimpresiones facsimilares de revistas de imágenes corporales publicadas en los Estados Unidos en los años cincuenta y sesenta, que han jugado un papel clave en la formación de la identidad sexual de los hombres de la generación de la Liberación Gay (Hooven III; Complete Reprint). Asimismo, se pueden encontrar referencias dispersas a publicaciones gay en los estudios históricos sobre la comunidad lésbica y gay, y de vez en cuando comentarios individuales en periódicos sobre publicaciones aliadas y rivales.

\footnotetext{
${ }^{2}$ Para ver listas de las organizaciones, consultar: http://www.ggb.org.br y http:// www.gentedobem.com.br
} 
Ha habido pocos estudios generales sobre los periódicos gay en su conjunto. Sin embargo, un artículo que ofrece algunos indicadores metodológicos útiles es "A Global View of the Gay and Lesbian Press”, de Evert Van der Veen, basado en una investigación llevada a cabo en el Departamento de Estudios Gay y Lésbicos de la Universidad de Utrecht (Países Bajos) entre 1984 y 1987. Van der Veen divide la historia de la prensa internacional gay en los siguientes periodos: 1) Antes de la Segunda Guerra Mundial, 1896-1933, cuando se desarrolló la primera ola de publicaciones abiertamente gay, particularmente en Alemania; 2) Periodo de ocultamiento, 1933-1967, con la restricción severa de las posibilidades para las publicaciones gay, primero por el nazismo y luego por la censura de la posguerra; 3) Periodo de explosión, 1968-1979, caracterizado por el advenimiento de la liberación gay y por las publicaciones políticas y comunitarias inspiradas en ese movimiento, y 4) Los ochenta, en los que el entretenimiento y la cultura se volvieron más importantes. A esta periodización podemos ahora agregar los noventa, en los que se dio la expansión del consumismo en una economía globalizada.

Se ha escrito relativamente poco sobre la prensa lésbica y gay brasileña. Fausto Neto estudia el modo en que la prensa convencional trató el asunto de las enfermedades vinculadas al SIDA de dos personajes célebres, Lauro Corona y Cazuza. Aunque es apenas mencionado en este trabajo, queda claro que hubo un fuerte ingrediente de homofobia involucrado en ese tratamiento. Las publicaciones gay, particularmente el periódico mensual Lampião da Esquina, son estudiadas en las historias más importantes que se han escrito sobre la comunidad y el movimiento gay del Brasil (Green, Além; Macrae). Aquiles Brayner ha realizado un análisis muy documentado de Lampião en su tesis doctoral para la Universidad de Leiden, algunos de los artículos de Lampião han sido publicados en forma de libro y varios seminarios y conferencias se han ocupado del periodismo gay (Brayner; Moreira; Monteiro). Escritores de publicaciones periódicas gay comentan de vez en cuando otras publicaciones, y ocasionalmente se ha informado sobre asuntos vinculados a la prensa gay en los medios convencionales, especialmente, los intentos de la policía federal para prohibir Lampião y los escándalos alrededor de algunas de las celebridades que aparecieron en G Magazine.

Es posible señalar cuatro factores clave en el desarrollo de la prensa gay en el Brasil:

1. Los desarrollos en la propia comunidad lésbica y gay. Los últimos cuarenta años han sido testigos de una visibilidad, una autoconfianza y una afirmación crecientes entre lesbianas y gays en todo el mundo, y este proceso ha tenido su equivalente en el Brasil. Ha habido una floreciente subcultura gay en las mayores ciudades, como Río de Janeiro y São Paulo, al menos desde fines del siglo xix. La rápida urbanización, los cambios en las relaciones de género, la influencia del feminismo y las filosofías de vida alternativas, y el impacto creciente de la cultura gay internacional a través de la globalización han estimulado el crecimiento de una comunidad gay autoconsciente, mientras muchos aspectos de la vida gay específica del Brasil han continuado prosperando (Green, Além). En los últimos veinte años la epidemia del SIDA ha afectado particularmente a los hombres gay, tanto en el Brasil como en otros lugares, causando muchas muertes trágicas pero también dando lugar a una movilización de la militancia.

2. El contexto político y económico nacional. El crecimiento del movimiento internacional de liberación gay a comienzos de los setenta coincidió con el periodo más 
represivo del régimen militar en el Brasil. A pesar de que los homosexuales no fueron blanco directo de la represión, la censura en la prensa y la atmósfera de miedo e intimidación inhibieron efectivamente el desarrollo del movimiento gay o de la prensa gay en ese periodo. La fundación de Lampião y el crecimiento explosivo del movimiento gay brasileño a fines de los años setenta formaron parte de una liberalización política general o “abertura” [apertura] producida a medida que los militares comenzaban a dejar el poder. La declinación de la militancia gay coincidió con la decepción política y la crisis económica de los años ochenta, mientras que la estabilización financiera y política y la globalización en los años noventa fueron acompañadas de un resurgimiento del movimiento y las publicaciones gay.

3. Los desarrollos en la tecnología de impresión. En el Brasil, como en otros lugares, los desarrollos en esta tecnología, tales como el mimeógrafo, la fotocopia, el offset y la autoedición digital han abaratado y facilitado las publicaciones. Esto ha permitido que grupos y organizaciones relativamente pequeñas publicaran sus opiniones y ha ido borrando crecientemente la distinción entre prensa alternativa y convencional. El crecimiento de la Web significa un paso más en esta dirección.

4. Las preocupaciones prácticas que enfrentan todos los medios gráficos, como el contenido, el público al que se dirigen, los costos de producción e impresión, la distribución, la circulación, la publicidad y, en el caso de la prensa alternativa, la censura.

Siguiendo la metodología de Van der Veen, la historia de los periódicos gay brasileños puede ser dividida en tres periodos principales: 1) los sesenta; 2) fines de los setenta y los ochenta, y 3) los noventa. Éstos pueden ser agrupados, asimismo, en seis grandes categorías según criterios de editor, público y contenido:

1. Boletines y pequeños periódicos publicados por grupos, constituidos formal o informalmente, como medios de comunicación con sus miembros y con el círculo inmediato de conocidos y contactos personales.

2. Periódicos imbuidos de las preocupaciones políticas y culturales del movimiento gay, pero dirigidos tanto a los gays como a la comunidad en general.

3. Publicaciones lésbicas.

4. Revistas comerciales que fomentan el estilo de vida del consumidor gay.

5. Publicaciones eróticas, con desnudos masculinos pero que excluyen escenas sexuales explícitas.

6. Publicaciones en serie sobre el SIDA, dirigidas tanto a profesionales de la salud como a la población con HIV/SIDA.

Inevitablemente estas categorías se superponen. Muchos de los grupos que publican boletines forman parte del movimiento gay más amplio, mientras que consejos para la prevención del SIDA aparecen también en boletines gay y revistas de estilo de vida consumista. Las revistas comerciales contienen noticias sobre la comunidad gay así como notas de estilo de vida. Un factor importante son los medios de distribución. Las revistas comerciales y las publicaciones eróticas se consiguen hoy en los puestos de venta de las mayores ciudades y son así visibles y accesibles a un público amplio, tanto gay como no gay. Las series sobre SIDA se benefician del apoyo oficial y los subsidios. Los boletines y los periódicos de la comunidad tienen las fuentes de financiación y los sistemas de distribución más precarios, aunque algunos de ellos sean los de vida pública más 
prolongada. Hay también algunas pocas publicaciones periódicas que no encajan nítidamente en ninguna de estas categorías. ${ }^{3}$

La primera ola de periódicos gay apareció en los años sesenta, gracias a la accesibilidad del mimeógrafo. Éstos fueron publicados por grupos informales de hombres gay, principalmente en Río de Janeiro y Salvador. Los colaboradores generalmente se identificaban como "bonecas" o gay afeminados e invariablemente usaban nombres de mujer. Estas publicaciones contenían noticias, chismes (“fofocas”), relatos de viajes y algunos artículos breves, como también dibujos lineales de figuras con ropa femenina. Usaban estampados con estarcidor en púrpura o negro, llegaban a varias páginas y frecuentemente estaban numeradas y fechadas, si bien de modo algo errático. La de mayor duración fue $O$ snob, producida en Río de Janeiro desde 1963 hasta 1969 por Agildo Guimarães. Otras fueron Baby (Salvador, 1969), Darling (Río de Janeiro, 1968), Le Femme (Río de Janeiro, 1968-1969), Gay Society (Salvador, 1968), Le Sophistiqué (Campos, 1966) y O Tiraninho (Salvador, sin fecha). Estas publicaciones circulaban entre amigos y conocidos y también eran distribuidas en lugares de encuentro gay. Incluso existió una incipiente Associação Brasileira da Imprensa Gay hacia fines de los años sesenta. Muchos de estos periódicos cesaron su publicación en 1969, tras la declaración del represivo Acto Institucional $N^{0} 5$, por temor a que fueran tomados como publicaciones subversivas (Green, Além 325; Fry; Míccolis; Míccolis \& Daniel 96-116).

En 1976, a medida que se aflojaba la represión de la dictadura militar y se iniciaba la "abertura", se reanudaron las publicaciones gay. El Boletim Informativo da Caixinha se hacía por fotocopiado, con el título de la publicación hecho en tipografías que se compraban preimpresas. Publicó unos diez números con una frecuencia aproximadamente mensual a lo largo de 1976. Contenía algunos artículos serios así como noticias sociales y chismes. Los colaboradores ya usaban sus nombres reales masculinos. Este boletín fue seguido por Gente Gay -también editado por Agildo Guimarães en Río de Janeiro-, que se publicó a lo largo de 1977 hasta fines de 1978, época para la que adoptó el formato tabloide. Mientras tanto, en São Paulo hubo dos intentos breves de producción de periódicos en 1977, Entender y Mundo Gay: o Jornal dos Entendidos. Estas publicaciones constituyeron algunos de los precursores de Lampião da Esquina, el más influyente de los periódicos gay brasileños.

Lampião tuvo un curioso comienzo. En septiembre de 1977, Winston Leyland, el editor del periódico cultural de San Francisco, Gay Sunshine, visitó el Brasil a fin de recolectar material para una antología en traducción inglesa de escritores gay latinoamericanos (más tarde publicada como Now the Volcano). Su visita fue organizada por João Antônio Mascarenhas, por entonces el único suscriptor del Gay Sunshine en Sudamérica. Leyland obtuvo un préstamo de la U.S. National Endowment for the Arts, lo que despertó el interés de los medios e hizo que Leyland fuera entrevistado por periodistas de la prensa general. Como resultado de la publicidad y de los contactos creados por esta visita, una cantidad de militantes gay decidió publicar un periódico gay. El primer número,

\footnotetext{
${ }^{3}$ Ver http://www-sul.stanford.edu/depts/hasrg/latinam/balder.html para una lista más completa de estos periódicos. He ofrecido algunas fechas para las ediciones conocidas pero el periodo real de publicación puede ser mayor.
} 
experimental, de Lampião fue publicado en abril de 1978 y los 37 números siguientes y 4 ediciones especiales aparecieron hasta el cese de su publicación en junio de 1981. En agosto de 1978 el gobierno federal inició un intento de silenciar la publicación abriéndole una causa policial bajo la acusación de contravención de la moral y el orden público que sancionaba la ley de prensa. Lampião logró asegurarse el apoyo de periodistas y figuras políticas en general, y las protestas llevaron a que el caso fuera cerrado a fines de 1979 (Mascarenhas; Macrae 65-93, 162-171).

Lampião introdujo rupturas innovadoras en varios sentidos. Entre los editores había periodistas, escritores y otros intelectuales, con el resultado de que se produjo con un nivel profesional, en formato tabloide, y también mantuvo un alto nivel cultural e intelectual en sus debates. Lampião se publicaba en Río de Janeiro, pero muchos de sus editores vivían en São Paulo, y la responsabilidad editorial era compartida entre las dos ciudades. El periódico apareció regularmente con una frecuencia mensual y se vendía abiertamente en los puestos de venta de periódicos, así como también por suscripción. La tirada inicial fue de 10.000 ejemplares, pero luego aumentó a 15.000. El principal distribuidor comercial rechazó distribuirlo, pero se hicieron arreglos para que llegara a las mayores ciudades fuera de Río de Janeiro y São Paulo.

Los artículos cubrían un amplio espectro de temas, que incluían la conciencia gay, los derechos gay, la política gay, la discriminación y la violencia contra homosexuales, la represión policial, el ambiente gay, el cine, el teatro, la danza y la literatura gay, los travestis y los transexuales, la prostitución, el carnaval y la religión. También se incluían artículos reflexivos o doctrinarios, así como informaciones prácticas como por ejemplo guías gay por las mayores ciudades del Brasil y listas de grupos gay. Se hacían entrevistas a personalidades brasileñas simpatizantes de los gays, como Fernando Gabeira y Ney Matogrosso, a escritores latinoamericanos muy conocidos, como Manuel Puig, y a militantes gay extranjeros, como Dennis Altman, Daniel Guérin y Guy Hocquenghem. Informaba sobre la situación de los gays en otros países latinoamericanos, especialmente Argentina y Cuba, pero también México y Colombia, así como en Europa y los Estados Unidos. Desde su primer número, Lampião intentó conscientemente llegar a las otras minorías, particularmente a las mujeres, los negros, los indios y el movimiento ecológico. Asimismo intentó sin éxito que se incorporaran lesbianas en el grupo editor, aunque éstas sí colaboraron con algunos artículos.

Lampião adoptó un diseño periodístico profesional y un estilo discursivo vivaz, coloquial, basado en el argot gay, que estableció un inmediato contacto con sus lectores. Un rasgo característico fue el uso del término del argot "bicha” [marica] y expresiones similares en vez del más formal "homosexual” o el término más en clave “entendido". Este uso de términos peyorativos resultó chocante para algunos lectores, pero, como explicó su editor, Aguinaldo Silva, fue una política deliberada: "Lo que pretendemos es rescatarlos del vocabulario machista para enseguida desmitificarlos” (I.3 (25 julio-25 agosto 1978): 5). El uso creativo de palabras hasta entonces receladas contribuyó a dar un tono informal al periódico. La sección regular de chismes se titulaba "Bixórdia" (de "bicha” y "mixórdia" [mezcolanza]) y cuando aparecieron fotos de hombres, fueron encabezados por el término "Bofarada", de "bofe" [macho] y "baforada” [bocanada de humo de cigarro o de mal aliento]. A pesar de que predominaba el sabor carioca, no se ignoraron otras áreas 
del Brasil. Por ejemplo, una nota sobre una compañía de teatro experimental en Recife fue titulada, usando el término del argot local para hombres gay, "Vivencial Diversiones apresenta: frangos falando para o mundo” (II.18 (noviembre 1979): 15). El uso satírico del lenguaje alejó a algunos lectores y provocó acusaciones de elitismo. Por ejemplo, un informe serio sobre la vida gay en la Zona Norte, una zona pobre y poco elegante de Río, fue titulada (en inglés): “Madureira by night” (I.8 (enero 1979): 16). A mediados de 1980 hubo una serie de ataques de grupos de derecha a los puestos que vendían la prensa alternativa. Por primera vez Lampião apareció una semana más tarde, con su número 28 en septiembre de 1980, y desde entonces, con la violencia creciente en la sociedad, sumada a la presión económica, un tono más pesimista se instaló en sus páginas. Muchos aspectos de Lampião fueron cuestionados, pero considerada en su totalidad significó una divisoria de aguas al ofrecer a la comunidad gay una nueva autoconfianza y una mayor visibilidad.

Los finales de la década de los ochenta y los comienzos de los noventa fueron un periodo de desencanto político y caos financiero, con el ingrediente del inicio de la epidemia del SIDA. El movimiento gay, que había surgido en los años 1978-1980, decayó rápidamente después de 1982 y hacia mediados de los años ochenta sólo un puñado de grupos continuó su existencia. Sin embargo, los periódicos gay siguieron apareciendo y al menos dos de ellos tuvieron una vida relativamente prolongada. La revista Okzinho fue publicada por el grupo Turma OK en Río, sostenida por Agildo Guimarães, quien venía siendo muy activo en publicaciones desde los años sesenta. La revista parece haber sido producida tanto por fotocopia como por mimeógrafo, y consistió en una mezcla de noticias internas del grupo y recortes de periódicos, con el objeto de aumentar la conciencia gay. Comenzó a salir en diciembre de 1984, continuó en 1985 y 1986 y todavía era publicada en 1991 bajo el título de Jornal Okzinho.

En Salvador, el militante Grupo Gay da Bahia o GGB, fundado en 1980, comenzó publicando el Boletim do Grupo Gay da Bahia en 1981, que se publicó regularmente hasta 1997 y luego en forma de informes ocasionales. El Boletim do GGB informaba sobre las actividades del grupo y asumió una posición combativa en apoyo de las campañas promovidas por éste. El GGB fue también una de las primeras organizaciones gay en Brasil en reconocer el peligro del SIDA, refiriéndose a ello en el Boletim número 3, de abril de 1982 (I.3 (abril 1982): 5), y luego en realizar campañas para que se llevaran adelante más acciones que frenaran la dispersión de la enfermedad.

Otros grupos gay de todo el Brasil continuaron publicando boletines y pequeños periódicos a lo largo de los años ochenta y noventa. En Río de Janeiro, el grupo Triângulo Rosa cooperó con las campañas del GGB y coordinó en 1987 el fracasado intento de persuadir al Congreso para que se penara en la Revisión de la Constitución Federal la discriminación en el terreno de la orientación sexual. Este grupo produjo un pequeño Boletim informativo (1986-1988), dactilografiado y reproducido por fotocopia, como también una pequeña publicación de corta duración llamada Triângulo Rosa (1986). Otras publicaciones eran la Folha de Parreira (1993-1997) del Grupo Dignidade y Turma da Batalha (1994-1998) del Grupo Esperança, ambos de Curitiba; Journal des Amis (19941995) de Les Amis Club en São Paulo y O Grito (1994) de la Comunidade Fratriarcal en Natal. El Boletim GTPOS (Grupo de Trabalho e Pesquisa em Orientação Sexual, 19951996) en São Paulo y Sexualidade: gênero e sociedade (1995), del Programa de Estudos 
e Pesquisas em Sexualidade, en Río de Janeiro tuvieron un carácter más académico, en completa oposición a Monänoz (1995), una revista de confección muy amateur realizada por un grupo anarco-punk.

Hubo relativamente pocas publicaciones dirigidas a lesbianas. La más importante entre las primeras que se hicieron fue Chanacomchana, editada por el Grupo Ação Lésbica Feminista en São Paulo durante los años ochenta. Un número de prueba de 1983 contiene un informe sobre una protesta en un bar lésbico que había tratado de prohibir la distribución del periódico, un artículo argumentando en favor de la autonomía de los grupos feministas respecto de los partidos políticos, el relato de una persona sobre su asunción pública como lesbiana y un artículo sobre la función del homosexual en la sociedad. Otros periódicos lésbicos publicados en los noventa fueron Um Outro Olhar (1995-), Femme (1995-1996) y Ousar Viver (1995-1998), una pequeña publicación sostenida por el Ministerio de Salud.

La publicación de periódicos gay revivió en los noventa. Una publicación notable fue Nós por Exemplo (1991-1996), que contó con una impresión de la más alta calidad en buen papel y fue una obra de arte por derecho propio. Combinaba noticias y artículos culturales con fotografías artísticas en blanco y negro hechas por el fotógrafo de origen boliviano Eduardo Velásquez. Fue sostenida económicamente por una institución de salud pública como un vehículo de transmisión para su sección suelta sobre SIDA Agaivê hoje y fue distribuida en Río, São Paulo y otras grandes ciudades. Durante el mismo periodo, una pequeña revista llamada Ent\& (1994-1995) circuló en Río, con noticias, reseñas, una guía gay y notas personales.

La aparición de Sui Generis en los puestos de venta a fines de 1994 representó una gran innovación. Ésta era una revista en colores impresa en papel ilustración, con un aspecto consumista y cosmopolita de un tono optimista. Contenía artículos y entrevistas a personalidades gay y simpatizantes de los gays, noticias sobre el Brasil y el exterior, notas especiales sobre moda masculina y reseñas de música, cine, video y libros, así como también artículos sobre historia, literatura y cultura gay. Durante buena parte de su existencia tuvo una página fija dirigida especialmente a las lesbianas. Traía entrevistas a cantantes como Ney Matogrosso, Renato Russo, Cássia Eller y Adriana Calcanhoto, el escritor Caio Fernando Abreu y el transexual Roberta Close, así como también a figuras intelectuales importantes como Roberto DaMatta y la política pro-gay Marta Suplicy, que más tarde se convirtió en alcaldesa de São Paulo. Sui Generis pasó por una serie de cambios durante su vida y a pesar de que predominaban las notas sobre estilo de vida para el consumidor gay y sobre la cultura popular, también contenía una cantidad importante de material sobre la comunidad lésbica y gay, particularmente en sus últimos números. Sui Generis fue distribuida por un distribuidor comercial y expuesta en muchos puestos de venta junto con las revistas de interés general. Tuvo un momento de dificultad cuando el distribuidor rechazó la tapa del número 44, que mostraba a dos hombres besándose, y ese número tuvo que venderse con una cobertura plástica como las revistas pornográficas. Sui Generis no consiguió atraer publicidad convencional en una cantidad significativa, pero sin embargo salió durante cinco años, hasta marzo de 2000, con el número 55.

En la actualidad, los puestos de venta están dominados por G Magazine, revista en colores y en papel ilustración, que ofrece fotografías de desnudos masculinos completos 
y frontales, incluyendo una serie de muy conocidos actores, cantantes y bailarines. Desde el cierre de Sui Generis, aquella publicación ha asumido crecientemente el rol de revista de noticias de la comunidad, incluyendo notas, reseñas y artículos cortos. G Magazine encabezó los titulares de los diarios nacionales cuando Vampeta, uno de los principales jugadores del equipo de fútbol Corinthians, y más tarde su compañero de equipo Dinei aparecieron desnudos en la revista. Se informó que le habían pagado 100.000 reales a Vampeta por la sesión de fotos, una enorme suma que indica la fuerza del real rosa y muestra cuán lejos han llegado las publicaciones gay desde los pequeños periódicos mimeografiados de los años sesenta.

A lo largo de los años ha aparecido un gran número de revistas eróticas ofreciendo desnudos masculinos. Se incluyen Pleiguei/Jornal do Homo, un revista de corta duración que sucedió a Lampião en 1981, Coverboy, Alone, Gato y Sex Symbol. En la actualidad, las publicaciones principales en esta área son Homens, Gold y Travestis, una revista de gran trayectoria que se especializa en fotos de desnudos de travestis brasileños. Contienen también una cierta cantidad de texto, información y avisos publicitarios. Se puede encontrar información sobre el ambiente gay en Jornal Grito $G$, un periódico en formato tabloide, gratuito, de frecuencia mensual, publicado en Niterói, y Babado, un periódico similar publicado en Campinas. En la misma ciudad, hay una revista hecha por drag queens, Zoom Mix Magazine, que tiene también su propio sitio en la Web.

Entre los grupos gay, el Grupo Gay da Bahia está muy consolidado y tiene su propio edificio en el centro histórico de Salvador. El reconocimiento oficial a su labor en la prevención del SIDA le ha permitido emprender un programa activo de publicaciones. Habitualmente publica Homo Sapiens (1997-), un periódico gratuito en formato de diario editado por Marcelo Cerqueira. Homo Sapiens, sucesora del Boletim do GGB, contiene noticias, reseñas de libros, direcciones útiles y artículos sobre temas gay, con un énfasis en la importancia del orgullo gay y los derechos humanos. Otros periódicos auspiciados por el GGB son: Aláfia: Jornal do Povo do Axé (2000-), una pequeña publicación trimestral dirigida a un público negro, y Princesa: Boletim da Associação de Travestis de Salvador (2001-), destinada a travestis. Ambos ponen el énfasis en el mensaje de prevención del SIDA. En Fortaleza, el grupo de prevención del SIDA GAPA-CE publica IDentidade (1999-), una pequeña revista en papel ilustración dirigida a gays. La institución principal que se ocupa de la prevención del SIDA es la Associação Brasileira Interdisciplinar de AIDS o ABIA en Río de Janeiro. Ésta publica el Boletim ABIA (1988-) y el Boletim Arayê (1995-), y traduce y distribuye la edición brasileña de Boletim Ação Anti-AIDS (1988-), compilado en Londres. Tiene un importante centro de información, que ha publicado una bibliografía de todo su material sobre homosexualidad (Associação Brasileira Interdisciplinar de AIDS).

Los periódicos tienen características especiales, cuya significación cultural e histórica se diferencia de los libros. Ellos son, en primer lugar, un emprendimiento colectivo y generalmente presuponen la existencia de un grupo de gente con intereses compartidos, tanto entre los productores que se encargan de escribirlos y publicarlos, como entre los que forman parte de su público suscribiéndose a ellos, comprándolos o leyéndolos. Aun siendo efímeros, ellos representan y crean una comunidad de intereses que se prolonga en el tiempo. Ofrecen a sus lectores el acceso a la información sobre lugares físicos, estilos de 
vida, intereses culturales y opiniones políticas de la comunidad gay y lésbica y, por lo tanto, una oportunidad de convertirse en miembros de la comunidad. Para lesbianas y gays jóvenes que están recién aproximándose a su sexualidad, los periódicos ofrecen un lazo y un medio de apoyo vitales. A través de los tópicos que eligen cubrir y de su discurso contribuyen a definir y propagar la cultura de la comunidad.

Sólo una pequeña proporción de la prensa lésbica y gay está directamente ligada al movimiento gay organizado, pero todas las publicaciones están orientadas a servir a la comunidad lésbica y gay en un sentido u otro, sea por razones políticas, sociales o comerciales. Todas enfrentan el mismo problema de decidir quiénes integran tal comunidad, cuáles son sus intereses y cómo debería ésta relacionarse con el resto de la sociedad. Para los periódicos, éste es un asunto crucial porque su supervivencia en la circulación depende mucho de ello. Las cuestiones de la identidad grupal, la estigmatización y la autoafirmación, los lazos colectivos y las dificultades para relacionar los movimientos sociales con la acción política han sido objeto de mucha teorización, en relación tanto con las lesbianas y los gays como con otros grupos excluidos. Conceptos sociológicos como la labelling theory [teoría del etiquetamiento], la identidad étnica y las teorías de los movimientos sociales han influido en el desarrollo del movimiento lésbico y gay en todo el mundo, y esto puede verse reflejado en la estrategia y en el discurso tanto de los periódicos como de los grupos organizados (Cohen; Engel; Epstein; Gamson; Plummer). Ahora examinaremos con más detalle cuatro publicaciones brasileñas: Lampião, Sui Generis, Boletim do Grupo Gay da Bahia y G Magazine, para ver cómo estas cuestiones han sido tratadas tanto en relación con sus lectores como con la sociedad en general. ${ }^{4}$

El primer editorial de Lampião estableció el manifiesto del periódico:

Brasil, marzo de 1978. Vientos favorables soplan en el sentido de una cierta liberalización del cuadro nacional [...] Pero, un periódico homosexual, ¿para qué? [...] Lo que nos interesa es destruir la imagen-patrón que se tiene del homosexual, según la cual éste es un ser que vive en las sombras, que prefiere la noche, que enfrenta su preferencia sexual como una especie de maldición, que es dado a los ademanes y que siempre tropieza, en cualquier intento de realizarse más ampliamente como ser humano, con este factor capital: su sexo no es aquel que él desearía tener. Para terminar con esa imagen-patrón, Lampião no pretende sollozar por la opresión nuestra de cada día, ni presionar válvulas de escape. Sólo recordará que una parte estadísticamente definible de la población brasileña [...] debe ser caracterizada como una minoría oprimida. Y una minoría, es elemental en los días de hoy, precisa una voz. [...] lo que Lampião reivindica en nombre de esa minoría es no sólo el asumirse y ser aceptado, lo que nosotros queremos es rescatar esa condición que todas las sociedades construidas sobre bases machistas les negaron: el hecho de que los homosexuales son seres humanos y que, por lo tanto, tienen todo el derecho de luchar por su plena realización, como tales. Para ello, estaremos mensualmente en los puestos de venta del País, hablando de actualidad y buscando iluminar sobre la

\footnotetext{
${ }^{4}$ Lampião da Esquina. Río de Janeiro: Lampião Editora. Nos. 0-año 3, nº 37, abril 1978-junio 1981; Sui Generis. Río de Janeiro: SG Press Editora. Nº 0-año VI, nº 55, 1994-22 marzo 2000; Boletim do Grupo Gay da Bahia. Año I, nº 1-año XVIII, nº 37, agosto 1981-enero/febrero 1998; G Magazine. São Paulo: Fractal Edições. 1997-.
} 
experiencia homosexual en todos los campos de la sociedad y de la creatividad humana. Nosotros pretendemos, también, ir más lejos, dando voz a todos los grupos injustamente discriminados -negros, indios, mujeres, las minorías étnicas del Kurdistán: abajo los guetos y el sistema (disfrazado) de parias. [...] (0 (abril 1978): 2)

Brevemente, el editorial establece una clara estrategia política (y de marketing) definiendo a los homosexuales como una minoría y ofreciendo la colaboración a otras minorías para mejorar su posición colectiva en la sociedad. Esta estrategia, basada en la experiencia de los movimientos de derechos civiles en los Estados Unidos y en otros lugares, se enmarca en los términos extraídos del discurso de liberación gay. El editorial fue titulado "Saindo do gueto" [Saliendo del gueto] y su texto realizaba el clásico pasaje de referirse a "el homosexual” y “él” en el comienzo para pasar, al final a la autoafirmación con "nuestra preferencia sexual” y "nuestro actuar". Hubo de ese modo una clara apelación a los lectores que se identificaban como homosexuales y a simpatizantes provenientes de otros grupos en los márgenes de la sociedad, que podían convertirse también en partidarios y lectores de la revista. En la práctica, Lampião fue mucho más efectiva en la apelación al rango de lectores identificado como gay, pero ambos aspectos de esta política demostraron ser problemáticos. El uso creativo del discurso coloquial y el empleo afirmativo de palabras previamente estigmatizadoras como "bicha" [marica] atrajeron a muchos lectores gay pero alejaron a otros. Esto fue señalado por Nando Ramos en un agudo artículo que apareció en otra publicación:

En verdad el propio periódico vive una situación muy contradictoria en relación con sus lectores. La relatividad del ser homosexual y la propia realidad del homosexual en el Brasil, ser inferior, impide a los lampiônicos compartir una identidad común con todos los otros homosexuales. En este sentido se busca una identidad a partir de premisas propias, muchas veces inaccesibles al homosexual prostituto, al travesti miserable, a la marica loca alienada. Como intelectuales, sus editores y colaboradores intentan abrir el gueto a la ventilación de ideas, volviendo más aireada la convivencia, o el confinamiento, la mayor parte de las veces, de los homosexuales. Sin embargo, un prejuicio sensible sobre ese homosexual lumpen, un deseo de reformarlo y no percibirlo como consecuencia de causas anteriores es flagrante y muchos lectores han señalado eso en sus cartas. (Ramos 4)

Algunos lectores objetaron el uso de "bicha", algunas mujeres se quejaron de que no había suficiente material sobre ellas y un travesti escribió para quejarse por la discriminación contra los travestis. Más tarde, el mismo desdén inicial, sentido por el periodista o incluido para desarmar la objeción de los lectores, puede verse en la introducción al primer informe sobre prostitución masculina (II.20 (enero 1980): 11-13). Sin embargo, como señaló Ramos, Lampião se fortaleció a partir de este intercambio de opiniones, publicando cartas críticas y creando un diálogo a través de modificaciones introducidas a partir de las sugerencias recibidas u ofreciendo razones para no aceptarlas. Después de responder a un lector particularmente crítico, el periódico observó:

De cualquier modo, preferimos recibir una carta como la suya, llena de restricciones, que las de habituales elogios” (III.30 (noviembre 1980): 19). La cobertura del travestismo, la 
prostitución masculina y otros aspectos de la subcultura homosexual fue incrementada, y se convirtió en una de las principales características de la publicación. Más tarde, hubo un debate sobre bisexualidad cuando este tema apareció en un polémico número (III.35 (abril 1981): 16)

El intento de atraer a otras minorías fue más problemático. Lampião publicaba regularmente notas sobre el movimiento de mujeres y logró obtener una entrevista con el líder negro Abdias Nascimento (II.15 (agosto 1979): 10-12), pero tuvo que admitir que estaba "bajo la permanente desconfianza de los otros grupos minoritarios" (II.21 (febrero 1980): 19) y que las otras minorías "desconfían de las máricas, sí” (III.30 (noviembre 1980): 18). Sin embargo, continuó con su línea editorial de abogar por una política de minorías hasta el final. Una estrategia alternativa que podía haber adoptado el periódico fue la de la política de los grupos de presión en los partidos políticos tradicionales. Cuando la sociedad civil se reconstituyó en el Brasil tras la dictadura militar, comenzaron a formarse los grupos gay, primero en São Paulo con Somos y luego en otros lugares del país. Algunos militantes gay eran también miembros de partidos políticos y se hicieron propuestas para estrechar vínculos con los dos partidos que mostraron algún interés en el movimiento gay, el recientemente formado Partido dos Travalhadores y el troskista Convergência Socialista. En la impetuosa atmósfera de liberalización, se inflamaron las emociones. Las diferencias personales y políticas condujeron a rupturas, entre las cuales la más famosa fue la división de Somos-SP (III.25 (junio 1980): 8).

Lampião alentó inicialmente el desarrollo del movimiento gay e informó extensamente sobre él. Sin embargo, se volvió crecientemente crítico a medida que los intentos de estrechar vínculos con los partidos políticos tomaban impulso, asumiendo eventualmente una actitud de franca hostilidad. Parece haber una serie de razones para esta ruptura. Una fue profesional: enfrentado a una cascada de textos de distintos grupos, el editor, Aguinaldo Silva, se negó a convertir al periódico en el órgano oficial del movimiento gay, argumentando con la necesidad de mantener el tono periodístico gracias al cual se llegó a los miles de lectores que de otro modo no se hubieran enterado sobre la existencia de esos grupos (II.27 (agosto 1980): 4). Otro punto de diferencia fue la relación entre el movimiento gay y los partidos políticos. Muchos miembros del grupo editor habían tenido experiencias negativas trabajando en los tradicionales partidos de izquierda y argumentaban en favor de la autonomía del movimiento gay (III.26 (julio 1980): 10-11; III.31 (diciembre 1980): 13-14). Las animosidades personales también parecen haberse sumado a la amarga disputa. Lampião se volvió cada vez más contra el movimiento gay entero, que trató en consecuencia de excluir al periódico de sus debates. Ambos colapsaron casi al mismo tiempo, en medio de recriminaciones mutuas.

Aunque trabajó en un clima político muy diferente en 1994, Sui Generis enfrentó problemas similares de definición de su público lector y sus relaciones con la sociedad. El manifiesto-editorial de Sui Generis usó el discurso de la globalización y el consumo: "No piense que el Village salió de NY y bajó en los barrios de los Jardins o en Ipanema. Pero, también por aquí, la cultura gay viene ganando espacio en estos años 90 . Entre las novedades que han surgido, se destaca el descubrimiento de que nosotros somos buenos comprando y, por lo tanto, merecemos del mercado una atención más acorde a nuestro 
poder de compra.” (0 (1994): 4). Sui Generis se inspiró en la nueva generación de revistas satinadas fomentadoras del estilo de vida del consumidor gay, que habían aparecido en los Estados Unidos y en Europa, particularmente la estadounidense Out y la inglesa Attitude (Monteiro). Estas revistas alcanzaron el éxito económico proveyendo a los anunciantes de un vehículo esterilizado para llegar al lucrativo mercado gay de clase media, si bien han sido acusadas de debilitar la cultura gay en el proceso de asimilación a los valores tradicionales (Chasin Harris). La marca de fábrica de Sui Generis, particularmente en sus primeros números, fue un cosmopolitismo entusiasta y juvenil, que abrazó la cultura popular internacional y mezcló notas sobre el ambiente gay en Río, Nueva York, Londres y São Paulo, reflejando la conmoción inicial de la apertura del Brasil al mercado global. Usó los términos "gay”, "lésbica” y "bisexual”, que por entonces habían pasado a ser de uso común en el Brasil, y un discurso compuesto por un argot gay contemporáneo ("bibi”, "barbie", "babado") mezclado con palabras en inglés. Como señaló la revista en un editorial sobre "Cultura gay”, en su tercer número, con Boy George en la tapa, “La cultura gay se está manifestando en el Brasil de la misma forma que en todo el mundo: sumamente cosmopolita en sus referencias. Como si gays de diferentes países hubiesen unido esfuerzos para combatir las resistencias locales e inaugurar una cultura común sin nacionalidad” (3 (mayo 1995): 7).

En una entrevista dada a otra publicación, el editor de Sui Generis, Nélson Feitosa, fue bien claro sobre esta visión estratégica:

\footnotetext{
El mundo cambió y es necesario responder a ese mundo. [...] la vieja militancia no tiene más opción. El mundo marcha hacia otro lado. [...] la cuestión homo tiene tres vías para avanzar: la del movimiento organizado, la de la afirmación individual de cada uno y la del poder económico. Para mí, las dos primeras, aun siendo importantes, son una consecuencia del último. [...] Cuando los gays saben usar ese poder económico, hacen que la gente descubra que no representan una amenaza, y que no tienen por qué discriminarlos. (Feitosa)
}

Esta estrategia también demostró ser fugaz en la práctica. El mensaje general de Sui Generis fue que "está bien ser gay” y esto trajo una respuesta entusiasta de sus lectores, que llenaron la redacción con cartas de elogios y relatos de sus propias experiencias de asunción pública de su sexualidad. Sin embargo, hubo algunas pocas voces disonantes: un lector pidió más modelos masculinos, un lector negro pidió más modelos negros, las mujeres reclamaban regularmente más material sobre mujeres y lesbianas, y muchos lectores se quejaban del alto precio de tapa, sugiriendo que estaba más allá del alcance de los gays más pobres. Muchos lectores se quejaron de que no entendían la terminología gay o las palabras extranjeras utilizadas y la revista tuvo que explicarlas. El tono dominante de la página de cartas de lectores fue el del elogio positivo, pero un par de editoriales respondiendo a críticas indican que se recibieron algunas opiniones adversas, que no fueron publicadas.

A pesar de su optimismo inicial, Sui Generis fracasó en su propósito de conseguir un apoyo significativo de los anunciantes tradicionales. La impresión dada por la sección de cartas y las entrevistas interminables a actores de telenovela en que la mayor parte de los 
lectores eran lesbianas y gays jóvenes que vivían con sus familias. La revista le ofreció a este sector vulnerable un invalorable lazo con la comunidad gay, pero, cualesquiera fueran sus aspiraciones a un estilo de vida gay, ellos no tenían los recursos económicos para interesar a esos anunciantes. El otro factor es el prejuicio homofóbico. Como explicó un agente publicitario, las principales compañías todavía eran renuentes al riesgo de “manchar” sus marcas anunciando en una publicación gay (VI.51 (10 enero 2000): 6-8, 10). Mientras Attitude, al compartir el mercado inglés con Gay Times, una revista mensual de larga trayectoria que todavía le da un lugar central a los intereses políticos y comunitarios, pudo concentrarse en las notas de estilo de vida orientadas al consumidor gay, Sui Generis tuvo que cumplir ambas funciones para conservar a sus lectores. En sus últimos números, aumentó la cantidad de espacio dedicada a los temas de la comunidad gay, con una página regular firmada por João Silvério Trevisan, un destacado historiador de la cultura y escritor gay, quien también había escrito para Lampião; con otra página iniciada por Luiz Mott, un antiguo militante gay, y con la cobertura de asuntos desagradables vinculados a la discriminación y a la violencia.

Los dilemas involucrados y las estrategias alternativas posibles pueden apreciarse prestando atención a otras dos publicaciones. Si bien posteriormente se hizo en imprenta, el Boletim do Grupo Gay da Bahia al comienzo se produjo con mimeógrafo, con una circulación muy limitada. El Boletim fue el órgano de un grupo gay militante liderado por Luiz Mott, uno de los militantes gay brasileños más destacados y enérgicos en los últimos veinte años, lo que le dio un rol claro: "nuestro Boletim es una de nuestras armas en la lucha contra todas las expresiones de prejuicio y discriminación antihomosexual” (II, 4 (septiembre 1982): 2). El GGB concentró sus esfuerzos en objetivos definidos, alcanzables, como el reconocimiento legal del GGB, la abolición del discriminatorio parágrafo 302.0 de la Clasificación Internacional de Enfermedades de la Organización Mundial de la Salud, la oposición a comentarios homofóbicos en la prensa convencional, especialmente el periódico local A Tarde, y la labor de prevención del SIDA. Desde su comienzo el Boletim do GGB publicó una lista de hombres gay, lesbianas y travestis que habían sido asesinados, confeccionada por miembros del grupo a partir de noticias de los periódicos. Más tarde, Mott pudo producir una nota basada en un análisis estadístico de estos casos, lo que condujo a un reconocimiento creciente en el Brasil y el exterior del prejuicio y la violencia contra los gays como un asunto de los derechos humanos. (Mott) Aunque de circulación limitada y aliado a muchos otros métodos de publicidad, el Boletim do GGB (y su sucesor Homo Sapiens) mostró las posibilidades de un periódico centrado en la promoción de la comunidad gay a través de la militancia gay.

Otra alternativa es la cultural. Las comunidades estigmatizadas toman fuerza de sus propias culturas. Las entrevistas a conocidos escritores, cantantes, directores de teatro y actores de TV, las reseñas de teatro, danza, música y literatura y los análisis en profundidad de cuestiones sociales e intelectuales publicados en Lampião, Sui Generis y otros periódicos ofrecen una amplia prueba de la contribución de lesbianas y gays a la cultura del Brasil y del mundo. Como contrapunto a las culturas alta y popular, hay también una subcultura transgresora, particularmente para hombres gays. En restrospectiva, algunas de las notas más interesantes en los últimos números de Lampião fueron informes en profundidad sobre aspectos de la subcultura gay, que por aquel entonces había sido tratada 
sólo por la prensa sensacionalista, pero que ahora era objeto de una intensa investigación académica. Algunos de estos temas fueron: áreas de búsqueda sexual (III.25 (junio 1980): 3), prostitución masculina (III.30 (noviembre 1980): 3-9), travestis (III.32 (enero 1981): 3-10) y hoteles para encuentros sexuales (III.34 (marzo 1981): 5-8). Estos temas fueron tratados de modo sofisticado: por ejemplo, una nota especial sobre la Plaza Tiradentes en el centro de Río de Janeiro, un área frecuentada por homosexuales pobres, describía la historia de la plaza, quiénes eran los propietarios de varios teatros y cines, la vida nocturna y los personajes bohemios, y la necesidad de preservar los edificios y el paisaje urbano sin echar a la gente que le daba al área mucho de su color local (III.36 (mayo 1981): 12-15).

El rol de los elementos transgresores de la cultura gay ha sido frecuentemente debatido. Los dilemas que enfrentan las publicaciones gay en la búsqueda del público de lectores quedan ilustrados por la pregunta acerca de los desnudos masculinos. El sexo vende, y donde la censura lo permite las publicaciones que muestran desnudos aparecen enseguida como parte del mercado pornográfico. La cuestión que se plantea es si esos desnudos deberían ser admitidos en las publicaciones gay que buscan una circulación mayor y un público respetable. Aunque los desnudos masculinos pueden aumentar la circulación, alejan a muchos lectores, particularmente a las lesbianas, y refuerzan los estereotipos del hombre gay obsesionado con el sexo. La cuestión fue planteada en el primer número de Lampião, que los rechazó sobre bases de principios: "no es nuestro género: Lampião cree que nadie [...] debe ser tratado como objeto sexual” (0 (abril 1978): 14). Más tarde, como la circulación caía, se reprodujeron algunas fotos de calidad pobre, en blanco y negro, y se ofreció un calendario con la publicación. El dilema fue notado por João Silvério Trevisan (“Entrevista”), quien más tarde recordó que un número dedicado a la situación de los gays en Cuba (III.33 (febrero 1981): 10-15), armado con gran dificultad, fue el que vendió la menor cantidad de ejemplares, mientras que el número siguiente, con un desnudo en la tapa, fue el de mayor venta de todos (Trevisan). A pesar de los pedidos de algunos lectores, Sui Generis no incluyó desnudos, poniendo al frente un consejo de un lector que había escrito: "Sería una pésima estrategia de marketing. Lo bueno de Sui es que podemos leerla en cualquier lugar e infiltrarla en otros tantos sin molestar a nadie, ni ser molestado por nadie” (22 (1997): 6). En lugar de ello, los editores inauguraron Homens, una publicación dedicada a ese mercado.

Una respuesta diferente al problema fue ofrecida por G Magazine, que, mientras cumplía crecientemente el papel de revista de cultura general para la comunidad gay, inauguró una sección especial de fotografías en color de desnudos masculinos, habitualmente posando con una erección completamente visible. Es difícil establecer el impacto de $G$ Magazine. Muchos de sus modelos son muy conocidos para el público general brasileño en las áreas de entretenimiento y deportes. La revista logró obtener unos pocos y ocasionales anuncios convencionales de productos como la bebida Red Devil o una concesionaria de Chevrolet, aunque es muy temprano para decir si ha logrado el entrecruzamiento entre pornografía y publicación convencional ejemplificado por la revista Playboy de Hugh Heffner (Dines). G Magazine ha tomado efectivamente uno de los íconos de la cultura de consumo, el culto a la celebridad, y lo ha subvertido con un antiguo símbolo del deseo transgresor homosexual, el desnudo masculino. Ésta parece ser una fórmula de marketing exitosa, pero queda por ver si esto va a asimilar a la cultura gay 
a la cultura general o llevarla de vuelta al gueto. Mientras tanto, ya está teniendo algunas consecuencias interesantes. Los simpatizantes del equipo de fútbol Corinthians han tenido que aceptar que sus ídolos aparezcan en revistas gay y las mismas celebridades han comenzado a pensar en las implicancias de su estatus como objetos sexuales (Huck).

Ya han pasado cuarenta años desde que aparecieron las primeras publicaciones periódicas lésbicas y gay del Brasil. Con la excepción de los años oscuros del régimen militar, se han venido produciendo publicaciones a lo largo de ese periodo. Han sido sostenidos por la comunidad lésbica y gay y a la vez han contribuido en la formación de esta comunidad y su cultura. Hoy son vendidos abiertamente en los puestos de venta, donde son accesibles a todo el mundo, pero todavía deben ser completamente aceptados por el público general, lo que se mide por la presencia de anuncios publicitarios. $G$ Magazine está a una gran distancia del idealismo político de Lampião aun cuando ambos cumplen una función común. Su presencia visible ayuda a individuos gay y lesbianas a participar en la cultura y la comunidad gay y, al mismo tiempo, sirve como un recordatorio a la sociedad en su conjunto sobre la existencia de la comunidad lésbica y gay en su propio seno.

Crecientemente, las publicaciones periódicas impresas tienen que coexistir con la Web. La Web ofrece un acceso sin precedentes a la información, no sólo en el Brasil sino también en el exterior. Actualmente, el acceso está limitado a aquellos que pueden sostenerlo económicamente, una importante restricción para muchos brasileños, de modo que mucho va a depender de que la Internet pueda volverse accesible a un público más amplio. Algunas de las publicaciones han comenzado a hacer uso de la Web. G Magazine tiene su propio sitio en ella y se puede acceder a versiones electrónicas del boletín del GGB, Homo Sapiens, y la revista de drag queens, Zoomgls. ${ }^{5}$ Para aquellos que tienen acceso a la red, la comunidad gay virtual está desarrollándose en la Internet. Habrá que ver cuál es el futuro para las revistas impresas. En el presente, vale la pena observar que $G$ Magazine está reimprimiendo algunos de sus primeros números y algunos números atrasados de Sui Generis están todavía en venta para los que tratan de completar sus colecciones. Esto sugiere que algunos gays y lesbianas brasileñas ven las revistas como parte de la memoria colectiva de su comunidad.

Traducción: Jung Ha Kang

BibliografíA

Aquino, Maria Aparecida de. Censura, Imprensa, Estado Autoritário (1968-1978) O Exercício Cotidiano da Dominação e da Resistência: 'O Estado de São Paulo' $e$ 'Movimento'. Bauru: EDUSC, 1999.

Associação Brasileira Interdisciplinar de AIDS. Homossexualidade e AIDS no Brasil. Catálogo do Centro de Documentação e Recursos. Río de Janeiro: ABIA, 2000.

${ }^{5}$ http://www.gmagazine.com.br; http://www.ggb.org.br; http://www.zoomgls.com.br 
Atton, Chris. Alternative Literature: A Practical Guide for Librarians. Aldershot: Gower, 1996.

Benjamin, Ionie. The Black Press in Britain. Stoke-on-Trent: Trentham, 1995.

Brake, Laurel, Aled Jones y Lionel Madden, eds. Investigating Victorian journalism. Basingstoke: Macmillan, 1990.

Brayner, Aquiles Ratti Alencar. “'Lampião’: um Bandido Social? Análise Discursiva da Revista Lampião da Esquina”. Diss. University of Leiden, 1998.

Chasin, Alexandra. "The Gay and Lesbian Press and the 'Business of Liberation'.” Selling Out: the Gay and Lesbian Movement Goes to Market. Nueva York: Palgrave, 2000. 57-100.

Cohen, Ed. "Who are 'We'? Gay 'Identity' as Political (E)motion (A Theoretical Rumination)”. Inside/Out: Lesbian Theories, Gay Theories. Diana Fuss, ed. Nueva York: Routledge, 1991. 71-92.

The Complete Reprint of Physique Pictorial. Köln: Taschen, 1997.

Dines, Gail. "II Buy it for the Articles': Playboy Magazine and the Sexualization of Consumerism”. Gender, Race and Class in Media: A Text-Reader. Gail Dines y Jean M. Humez, ed. Thousand Oaks: Sage, 1995. 254-262.

Engel, Stephen M. The Unfinished Revolution. Social Movement Theory and the Gay and Lesbian Movement. Cambridge: Cambridge University Press, 2001.

Epstein, Steven. "Gay Politics, Ethnic Identity: the Limits of Social Constructionism”. Socialist Review 17/3-4, 93-94 (1987): 9-54.

Erni, John Nguyet y Anthony J. Spires. “Glossy Subjects: ‘G\&L Magazine’ and 'Tonghzi' Cultural Visibility in Taiwan”. Sexualities 4/1 (2001): 25-49.

Fausto Neto, Antônio. Mortes em Derrapagem: os Casos Corona e Cazuza no Discurso da Comunicação de Massa. [Río de Janeiro]: Rio Fundo Editora, 1991.

Feitosa, Nélson. “Mostrando a cara”. Ent\& I/05 (09 nov. a 01 dic. 1994): 13-15.

Fry, Peter. "História da Imprensa Baiana”. Lampião da Esquina I/4 (25 agosto-25 septiembre 1978): 4.

Gamson, Joshua. “Must Identity Movements Self-Destruct? A Queer Dilemma”. Social Problems 42/3 (1995): 390-407.

Green, James N. Além do Carnaval: A Homossexualidade Masculina no Brasil do Século $X X$. São Paulo: Editora UNESP, 2000.

“The Emergence of the Brazilian Gay Liberation Movement, 1977-1981”. Latin American Perspectives 21/1 (Winter 1994): 38-55.

“'More Love and More Desire': the Building of a Brazilian Movement”. The Global Emergence of Gay and Lesbian Politics: National Imprints of a Worldwide Movement. Barry D. Adam, Jan Willem Duyvendak y André Krouwel, ed. Philadelphia: Temple University Press, 1999. 91-109.

"Desire and Militancy: Lesbians, Gays and the Brazilian Workers Party”. Different Rainbows. Peter Drucker, ed. Londres: Gay Men’s Press, 2000. 57-70.

Hanscombe, Gillian E. y Andrew Lumsden. Title Fight: the Battle for Gay News. Londres: Brilliance, 1983.

Harris, Daniel. “The Invention of the Teflon Magazine: From After Dark to Out”. The Rise and Fall of Gay Culture. By Harris. Nueva York: Ballantine, 1999. 64-85. 
Hooven III, F. Valentine. Beefcake: the Muscle Magazines of America, 1950-1970. Köln: Taschen, 1995.

Huck, Luciano. Entrevista, Roger José Noronha Silva: http://lucianohuck.zip.net/SiteLH/ Antena/Entrevista/roger.htm

Kennedy, Hubert. The Ideal Gay Man: The Story of 'Der Kreis’. Nueva York: Harrington Park Press, 1999.

Kunoff, Hugo. The Alternative Movement, Press, and Literature of West Germany. Wiesbaden: Otto Harrassowitz, 1988.

Leyland, Winston, ed. Now the Volcano: an Anthology of Latin American Gay Literature. San Francisco: Gay Sunshine Press, 1979.

Macrae, Edward. A Construção da Igualdade: Identidade Sexual e Política no Brasil da 'Abertura'. Campinas: Editora da UNICAMP, 1990.

Mascarenhas, João Antônio de. Entrevista personal, Río de Janeiro, 2 octubre 1997.

Míccolis, Leila. “‘Snob’, ‘Le Femme’... Os Bons Tempos da Imprensa Guei”. Lampião da Esquina III/28 (septiembre 1980): 6-7.

Míccolis, Leila y Herbert Daniel. Jacarés e Lobishomens: Dois Ensaios sobre a Homossexualidade. Río de Janeiro: Achiamé, 1983.

Minority Press Group. Here is the Other News: Challenges to the Local Commercial Press. Londres: Minority Press Group, 1980.

Monteiro, Marko. O Homoerotismo nas Revistas Sui Generis e Homens. Trabajo presentado en el Evento Literatura e Homoerotismo: II Encontro de Pesquisadores Universitários, Universidade Federal Fluminense, Instituto de Letras, 24-26 de mayo de 2000: http:/ /www.artnet.com.br/\%7Emarko/ohomoero.htm

Moreira, Antônio Carlos. Só para Cavalheiros: Crônicas Urbanas do Jornal Lampião. Río de Janeiro, 1997.

Mott, Luiz Roberto. Homofobia: A Violação dos Direitos Humanos de Gays, Lésbicas \& Travestis no Brasil. Salvador: Grupo Gay da Bahia; San Francisco: International Gay and Lesbian Human Rights Commission, 1997.

Plummer, Kenneth, ed. The Making of the Modern Homosexual. Londres: Hutchinson, 1981.

Ramos, Nando. "Enfim, um jornal-maravilha”. Artículo publicado en Singular \& Plural, março 1979, y reimpreso en Lampião I/12 (mayo 1979): 4.

Sanderson, Terry. Mediawatch: the Treatment of Male and Female Homosexuality in the British Media. Londres: Cassell, 1995.

Streitmatter, Rodger. Unspeakable: The Rise of the Gay and Lesbian Press in America. Boston: Faber \& Faber, 1995.

Trevisan, João Silvério. Devassos no Paraíso: a Homossexualidade no Brasil, da Colônia à Atualidade. $4^{\mathrm{a}}$ ed. Río de Janeiro: Editora Record, 2000.

“Entrevista a Sylvio de Oliveira, em 10/10/93, no Rio de Janeiro”. Nós por exemplo II/11 (Nov./dic. 1993): 4-5.

Van der Veen, Evert. “A Global View of the Gay and Lesbian Press”. Second ILGA Pink Book: A Global View of Lesbian and Gay Liberation and Oppression. Utrecht: Interfacultaire Werkgroep Homostudies, Rijksuniversiteit Utrecht, 1988. 14-32. 